\title{
Chemokine Receptor CCR1 Disruption Limits Renal Damage in a Murine Model of Hemolytic Uremic Syndrome
}

\author{
Maria V. Ramos, ${ }^{\star}$ Constance Auvynet, ${ }^{\dagger}$ \\ Lucie Poupel, ${ }^{\dagger}$ Mathieu Rodero, ${ }^{\dagger}$ \\ Maria Pilar Mejias, ${ }^{*}$ Cecilia A. Panek, ${ }^{*}$ \\ Silvia Vanzulli, ${ }^{\star}$ Christophe Combadiere ${ }^{\dagger}$ and \\ Marina Palermo* \\ From the Division of Immunology, Institute of Experimental \\ Medicine (IMEX-CONICET), and the Division of Pathology, \\ Institute of Oncologic Investigation, National Academy of \\ Medicine, Buenos Aires, Argentina; and the Laboratory of \\ Immunity and Infection, ${ }^{\dagger}$ INSERM UMRS 945, University of Pierre \\ and Marie Curie, Paris, France
}

Shiga toxin (Stx)-producing Escherichia coli is the main etiological agent that causes hemolytic uremic syndrome (HUS), a microangiopathic disease characterized by hemolytic anemia, thrombocytopenia, and acute renal failure. Although direct cytotoxic effects on endothelial cells by Stx are the primary pathogenic event, there is evidence that indicates the inflammatory response mediated by polymorphonuclear neutrophils and monocytes as the key event during HUS development. Because the chemokine receptor CCR1 participates in the pathogenesis of several renal diseases by orchestrating myeloid cell kidney infiltration, we specifically addressed the contribution of CCR1 in a murine model of HUS. We showed that Stx type 2-treated CCR1 ${ }^{-/-}$mice have an increased survival rate associated with less functional and histological renal damage compared with control mice. Stx type 2-triggered neutrophilia and monocytosis and polymorphonuclear neutrophil and monocyte renal infiltration were significantly reduced and delayed in $\mathrm{CCR}^{-/-}$mice compared with control mice. In addition, the increase of the inflammatory cytokines (tumor necrosis factor- $\alpha$ and IL-6) in plasma was delayed in $\mathrm{CCR} 1^{-/-}$mice compared with control mice. These data demonstrate that CCR1 participates in cell recruitment to the kidney and amplification of the inflammatory response that contributes to HUS development. Blockade of CCR1 could be important to the design of future therapies to restrain the inflammatory response involved in the development of HUS. (Am J Pathol 2012, 180:1040-1048; DOI: 10.1016/j.ajpath.2011.11.011)

Shiga toxin-producing Escherichia coli is the principal etiological agent of diarrhea-associated hemolytic uremic syndrome (HUS). HUS mainly affects children and is characterized by microangiopathic hemolytic anemia, thrombocytopenia, and acute renal failure. ${ }^{1-3}$ The incidence of HUS varies according to the country. Argentina shows the highest incidence worldwide, with 12 to 14 cases per 100,000 children aged $<5$ years per year and $>400$ new cases annually. ${ }^{4}$ This rate is 10 times higher than in other industrialized countries ${ }^{5}$ and remains a major health problem, with no specific treatment.

Endothelial damage has been recognized to play a central role in the sequence of events leading to the microangiopathic process of HUS. ${ }^{6}$ Human glomerular endothelial cells are the primary target of the toxic effects of Shiga toxin (Stx), which, on binding to its specific receptor Gb3, triggers a cascade of signaling events contributing to the development of vascular dysfunction, recruitment of leukocytes, platelet thrombus formation, and fibrin deposition. ${ }^{7}$ Moreover, in human endothelial cells, Gb3 expression and Stx toxicity are further increased by inflammatory cytokines, such as tumor necrosis factor (TNF)- $\alpha,{ }^{7}$ that can be released from monocytes/ macrophages (Macs) in response to Stx. ${ }^{8}$ There is considerable evidence that polymorphonuclear neutrophils $(\mathrm{PMNs})^{9}$ and monocytes ${ }^{10}$ play an active role in the

Supported in part by grants from INSERM, the Agence Nationale de la Recherche (ANR) Maladies Neurologiques et Psychiatriques (ANR-08MNPS -003), European Grant Innochem (LSHB-CT-2005-518167 to C.C.), and Agencia Nacional de Promoción Científica y Tecnológica from Argentina (PICT 08/417 to M.P). C.C. is a recipient of a contract (Interface) from Assistance Publique-Hopitaux de Paris.

Accepted for publication November 11, 2011.

C.C. and M.P. contributed equally to this work.

Address reprint requests to Maria Victoria Ramos, Ph.D., Ciudad Autonoma de Buenos Aires, Pacheco de Melo 3081, C1425AUM, Argentina. E-mail: mvramos@hematologia.anm.edu.ar or toresani7@hotmail.com. 
pathogenesis of HUS, and that their interaction with activated endothelial cells contributes to amplify microvascular injury in the kidney.

During the acute phase of the disease, PMNs are activated, become more adhesive, and damage the endothelium. ${ }^{11,12}$ Kidney biopsy specimens from children with HUS showed monocytes and PMNs within the glomeruli, along the zone of microvascular injury. ${ }^{13,14}$ Several reports described, in mice, that PMN infiltration in kidney is dependent on chemokine CXCL1/keratinocyte chemoattractant $(\mathrm{KC})$ and $\mathrm{CXCL} / \mathrm{Mac}$ inflammatory protein-2 local up-regulation, ${ }^{15}$ mainly chemokine ligand $(\mathrm{CCL})$ 2/monocyte chemoattractant protein-1 and CXCL8/L-8, two key modulators of monocytes/Macs and PMN adhesion and transmigration. ${ }^{16}$ Moreover, elevated urinary levels of these two chemokines in patients with HUS have been reported. ${ }^{16}$ Other chemokines, such as $\mathrm{CX}_{3} \mathrm{CL} 1 /$ fractalkine and its receptor, $\mathrm{CX}_{3} \mathrm{CR} 1$, have also been implicated in HUS. We previously reported that $\mathrm{CX}_{3} \mathrm{CR} 1$ is down-regulated on peripheral leukocytes from patients with HUS, ${ }^{17}$ and Zanchi et $\mathrm{al}^{18}$ showed that Stx induces the synthesis of $\mathrm{CX}_{3} \mathrm{CL} 1$ by human endothelial cells. Thus, locally secreted chemokines participate in the accumulation of inflammatory cells at kidney level ${ }^{15}$ and amplify the inflammatory processes instrumental to the activation of renal microvascular endothelial cells. Another chemokine axis, CCR1 and its ligand, has been implicated in renal diseases. ${ }^{19}$ CCR 1 is mainly expressed on PMNs, monocytes, lymphocytes, and eosinophils, and binds the chemokines Mac-inflammatory protein (CCL3/Mac inflammatory protein-1 $\alpha$ ) and regulated on activation normal T-cell expressed and secreted (CCL5), among other related chemokines. ${ }^{20-22}$ In particular, Macs are recruited into kidney from Stx plus lipopolysaccharide-injected mice, in response to CCL2, CCL5, and CCL3 secretion. ${ }^{23}$ CCL3 is produced by endothelial cells, epithelial cells, and leukocytes, and binds to CCR1 and CCR5 with high affinity to exert its biological effects. ${ }^{24-26}$

In the present study, we addressed the role of CCR1 in a murine model of HUS-inducing renal damage by i.v. Stx type 2 (Stx2) injection. We showed that CCR1-deficient mice $\left(\mathrm{CCR} 1^{-1-}\right)$ were less susceptible to Stx2 cytotoxic effects and showed higher survival rates than control mice. These data imply that CCR 1 may be an important chemokine receptor during inflammatory response in HUS evolution.

\section{Materials and Methods}

\section{Mice}

CCR1- and CCR5-deficient mice (CCR1 ${ }^{-1-}$ and $\mathrm{CCR}^{-1-}$ ) were generated as previously described. ${ }^{21,27}$ $\mathrm{CCR}^{-1-}$ were provided by Drs. Philippe Murphy and Ji Liang Gao (Laboratory of Molecular Immunology, National Institute of Allergy and Infectious Diseases, $\mathrm{NIH}$, Bethesda, MD). CCR5 ${ }^{-1-}$ (Jackson Laboratory, Bar Harbor, ME) and C57BL/6 control mice (weight, 18 to $22 \mathrm{~g}$ ) were maintained at the Centre d'Exploration Fonction- nelle animal facility (Pitié-Salpétrière, Paris, France). All deficient mice were bred onto the C57BL/6 background (six to eight backcrosses). Mice were housed in a 12hour light-dark cycle and maintained with food and water available ad libitum. Animal experiments were approved by the local Institutional Animal Care and Use Committee of Faculté of Medicine Pitié-Salpétrière.

\section{Murine Model of HUS}

Stx2 was prepared as previously described. ${ }^{28}$ Cytotoxic activity was evaluated on Vero cells, and the $\mathrm{CD}_{50}$ (cytotoxic dose that kills $50 \%$ of Vero cells) was calculated. ${ }^{29}$ Control and $\mathrm{CCR} 1^{-1-}$ mice were injected i.v. with a dose equivalent to $300 \mathrm{CD}_{50}$ that induced $>80 \%$ of mortality during the 6 days after injection. Mice were anesthetized, bled by puncture of the retro-orbital plexus, and subjected to necropsy at different times after Stx2 injection. Whole blood (100 $\mu \mathrm{L}$ ) was analyzed by flow cytometry. Animals were perfused with sterile PBS. Bone marrow cells were obtained from one femur and tibia. Lungs were homogenized and passed though a cell strainer (Becton Dickinson, Franklin Lakes, NJ), and the cells were washed and resuspended in PBS. Kidneys were incubated with collagenase type IV for 40 minutes, and cells were washed and sedimented on a Ficoll gradient to recover leukocytes.

\section{Flow Cytometry}

Leukocyte subpopulations were detected by flow cytometry using the standard procedures and the following monoclonal antibodies: anti-7/4-fluorescein isothiocyanate, CD11b-phycoerythrin (PE) Cy5, Ly6G-PE, CD11c-PE (BD PharMingen, San Diego, CA), and F4/80-antigen-presenting cell (Serotec, Oxford, UK). Cell suspensions were incubated with appropriate fluorochrome-conjugated antibodies and analyzed by flow cytometry (FACSCalibur; Becton Dickinson), using Cell Quest Pro software (Becton Dickinson). The absolute number of each leukocyte subpopulation was calculated as the total leukocytes multiplied by the percentage of cells inside the specific gate analyzed by flow cytometry. Total leukocytes in $1 \mathrm{~mL}$ were calculated using a predetermined number of beads (Polybead, carboxylate microsphere; Polysciences Europe, Eppelheim, Germany) added to each tube.

\section{Renal Damage Evaluation}

\section{Urea and Creatinine Evaluation}

Biochemical determinations of urea and creatinine in plasma were performed using commercial kits [QuantiChromTM Urea Assay Kit (DIUR-500) and Creatinine Assay Kit; BioAssay Systems, Hayward, CA], following standardized instructions.

\section{Histopathological Analyses}

For histological analysis, kidneys from control and $\mathrm{CCR}^{-1-}$ mice, excised before and after Stx2 injection, 
were bisected longitudinally; fixed in 10\% neutral formalin; and embedded in paraffin. Tissue sections $(4-\mu \mathrm{m}$ thick) were stained with H\&E and PAS before light microscopic examination. Renal tubular injury was evaluated according to the following criteria: swelling and cytoplasmic vacuolation, sloughing tubular epithelium, basement membrane integrity, necrosis, and apoptosis. The extent of damage was assessed by counting the number of affected tubules per cortical field. Glomerular changes were quantified as the number of hyperemic glomeruli per cortical field. All quantifications were performed by randomly counting 20 fields at $\times 400$ magnification for four independent sections from three mice.

\section{IHC Renal Evaluation of $\mathrm{F} 4 / 80^{+}$Cells}

Paraffin sections were fixed in xylene and rehydrated through ethanol and $1 \mathrm{~mol} / \mathrm{L}$ PBS (pH 6.0). Endogenous peroxidases were quenched with $3 \% \mathrm{H}_{2} \mathrm{O}_{2}$ in methanol, before blocking nonspecific binding with 1.5\% normal rabbit serum (ABC Staining System; Santa Cruz Biotechnology, Santa Cruz, CA) diluted in PBS. Sections were incubated overnight at $4^{\circ} \mathrm{C}$ with the primary antibody: rat anti-mouse F4/80 (dilution, 1:25; $0.5 \mathrm{mg} / \mathrm{mL}$; AbD Serotec, Oxford). The slides were washed and incubated with biotin-conjugated rabbit anti-rat IgG (dilution, 1:100; 0.5 $\mathrm{mg} / \mathrm{mL}$; Vector Laboratories, Burlingame, CA) for 40 minutes, followed by streptavidin-conjugated peroxidase and $3^{\prime}, 3^{\prime}$-diaminobenzidine (Vector Laboratories), and counterstained with hematoxylin.

\section{Immunofluorescent Staining of Renal Leukocytes}

To determine the presence of tissue-associated leukocytes, frozen kidney samples were embedded in optimal cutting temperature compound (Tissue Tek, Tokyo, Japan) and cut into sections ( $5 \mu \mathrm{m}$ thick) in a cryostat, fixed with cold acetone for 10 minutes, and blocked with $1 \%$ PBS-bovine serum albumin for 30 minutes. Sections were incubated overnight with the primary antibodies: rat anti-mouse Ly6G antibody (dilution, 1:100; $0.5 \mathrm{mg} / \mathrm{mL}$; BD Pharmingen, Franklin Lakes) or rat anti-mouse CD11b (integrin $\alpha$ M chain; MAC-1; dilution, 1:10; $125 \mu \mathrm{g} / \mathrm{mL}$; BD Pharmingen). The sections were washed with PBS and incubated with anti-rat Alexa 488-conjugated secondary antibody (dilution, 1:1000; 2 mg/mL; Invitrogen, Carlsbad, CA) for 2 hours. At the final step, sections were washed with PBS and mounted with VectaShieldHard Set mounting reagent (Vector Laboratories) containing 12.5 $\mu \mathrm{g} / \mathrm{mL}$ DAPI to identify nuclei. As a negative control, the same concentration of secondary antibody was used without any primary antibodies. Images were captured with a Coolsnap digital camera (RS Photometrics, Tucson, AZ) attached to an Olympus BX51 fluorescence microscope (Olympus, Rungis, France). For statistical analysis, digital quantification of $\mathrm{CD}_{11 \mathrm{~b}^{+}}$or $\mathrm{Ly}_{6 \mathrm{G}}{ }^{+}$ cells was performed using ImageJ software $(\mathrm{NIH}, \mathrm{Be}-$ thesda, MD).

\section{Measurement of Cytokines by ELISA}

Concentrations of murine TNF- $\alpha$ and IL- 6 were measured in plasma from control and CCR $1^{-1-}$ mice before or at various time points after Stx2 injection, using a standardized sandwich enzyme-linked immunosorbent assay (Quantikine R\&D Systems, Rochester, MN), according to the manufacturer's instructions. The optical density was determined at $450 \mathrm{~nm}$ in an enzyme-linked immunosorbent assay plate reader. Recombinant murine cytokines (Quantikine R\&D Systems) were used to generate standard curves, and concentrations were expressed as $\mathrm{pg} / \mathrm{mL}$.

\section{Statistical Analysis}

GraphPad Prism 5 (GraphPad Software, San Diego, CA) was used for data analysis and graphic representation. Data are presented as the mean \pm SEM of each group of mice. The Student's t-test was used for analysis of biochemical parameters of renal damage, flow cytometry data, and leukocyte counts obtained by kidney staining. The $\chi^{2}$ test was used for histological parameter analysis. The log-rank test was used to compare survival curves. $P<0.05$ was considered significant.

\section{Results}

\section{CCR1 ${ }^{-1-}$ Mice Are Less Susceptible to Stx2 Than Control Mice}

To determine whether chemokine receptor CCR1 is implicated in a murine model of HUS pathogenesis, CCR $1^{-1-}$ and control C57BL/6 mice were injected i.v. with Stx2 and survival rate was evaluated. As shown in Figure $1 \mathrm{~A}, 70 \%$ of the CCR1-deficient mice survived to Stx2 injection compared with $20 \%$ of control mice. Because CCR1 and CCR5 share several ligands, we also evaluated Stx2 cytotoxic effect in CCR5 $5^{-1-}$ mice. Survival in $\mathrm{CCR}^{-1-}$ mice showed no significant difference with control mice (Figure 1A). These data suggest that, even though CCR1 and CCR5 share their main ligands CCL3 and CCL5, CCR1 plays a critical role in HUS evolution. Because the main Stx2 target tissue is the kidney, renal function was evaluated by measuring urea and creatinine levels in plasma. The level of plasmatic urea increased 24 hours after Stx 2 injection and peaked by day 3 in control mice, whereas it increased slightly and belatedly in $\mathrm{CCR} 1^{-1-}$ mice (Figure 1B). Moreover, creatinine was only significantly increased in control mice at day 3 but not in $\mathrm{CCR} 1^{-1-}$ mice (Figure $1 \mathrm{C}$ ). These data suggest that the increased survival observed in $\mathrm{CCR} 1^{-1-}$ mice was associated with reduced renal damage.

\section{CCR1 ${ }^{-/-}$Mice Display Reduced Tubular Damage}

Because the kidney is the main target for Stx2 toxicity, renal tissue samples of both mouse strains were studied before and after Stx2 injection. Normal renal histological 
A

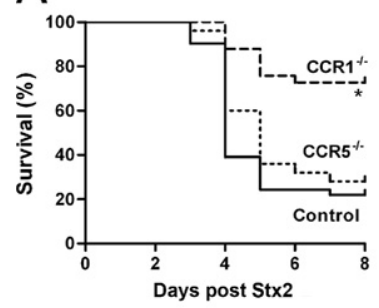

D

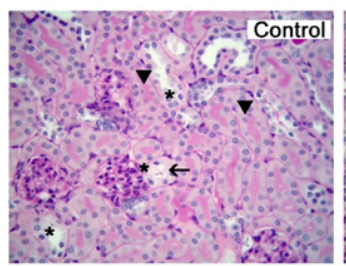

$\mathrm{F}$

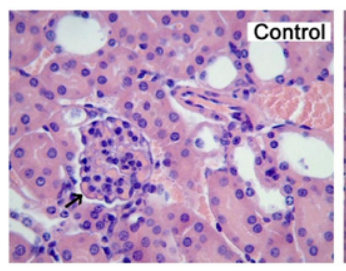

B
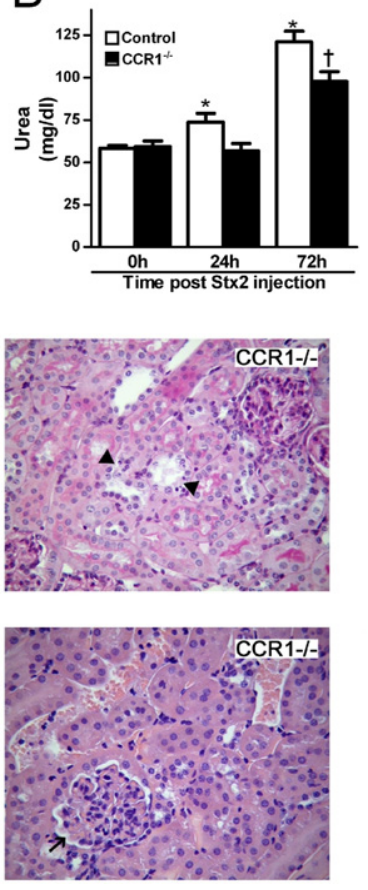

C

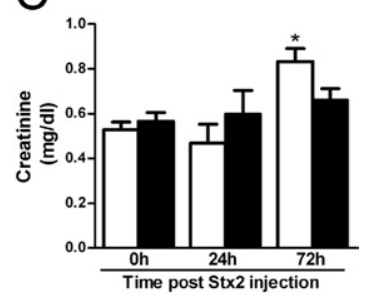

E

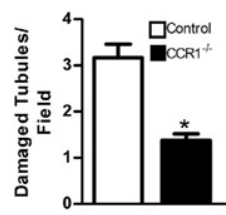

G

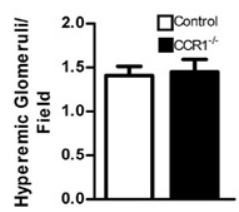

Figure 1. CCR $1^{-/-}$survival and renal damage after Stx2 intoxication. A: CCR $1^{-/-}(n=38)$, $\mathrm{CCR}^{-1-}(n=20)$, and control $(n=30)$ mice were injected i.v. with Stx2. The survival was monitored on a daily basis. ${ }^{*} P<0.001$ versus control; ${ }^{\dagger} P<0.05$ versus CCR $5^{-/-}$mice. Plasmatic urea $(\mathbf{B})$ and creatinine $(\mathbf{C})$ concentrations were measured at preintoxication (0 hours) or after Stx 2 administration (24 or 72 hours) in $\mathrm{CCR}^{-/-}$and control mice. Data represent mean \pm SEM values ( $n=15$ per group). ${ }^{*} P<$ 0.05 versus control preintoxication ( 0 hours); ${ }^{\dagger} P$ $<0.05$ versus $\mathrm{CCR} 1^{-/-}$preintoxication $(0$ hours). D: Representative PAS-stained sections from renal tissue of control and CCR $1^{-1-}$ mice showing Stx2-induced tubular injury after 72 hours. In control mice, more tubules showed focal necrosis, evaluated as tubular epithelial cells with eosinophilic and homogeneous cytoplasms and loss or picnotic nuclei (arrow heads), detachment from basement membrane (arrow), and cell sloughing (asterisks). Original magnification, $\times 200$. E: Number of damaged tubules in 20 cortical fields in control and CCR $1^{-/-}$mice. ${ }^{*} P<0.001$ versus control mice. Original magnification, $\times 400$. F: H\&E-stained sections from control and CCR $1^{-/-}$mice 72 hours after Stx 2 intoxication displaying hyperemic glomeruli and hyperemic vessels (arrow) in the interstitium. G: Number of hyperemic glomeruli counted in 20 cortical fields showed no difference between control and CCR1 mice. Original magnification, $\times 400$. characteristics were observed before treatment in both mouse strains. At 72 hours after intoxication, histopathological analysis showed damage mainly localized in renal tubules in CCR1 ${ }^{-1-}$ and control mice (Figure 1, D and E). The quantification of affected tubules showed significantly fewer damaged tubules in CCR $1^{-/-}$than in control mice (Figure 1E), indicating less extensive tubular epithelial necrosis in $\mathrm{CCR} 1^{-1-}$ mice. The damaged tubules exhibited swelling, cytoplasmic vacuolation, and sloughing of tubular epithelium in both mouse strains. Although tubules from both strains display apoptotic cells, a few tubules were completely necrotic $(2.5 \%)$ in control mice. This type of injury was absent in renal parenchyma from $\mathrm{CCR} 1^{-1-}$ mice, suggesting less severe lesions. The only glomerular change was manifested by hyperemia, but occluded glomeruli or amorphous material suggestive of intraglomerular fibrin deposits was not observed (data not shown). The quantification of hyperemic glomeruli was similar in both mouse strains (Figure 1, F and $G$ ). These results suggest that reduced renal dysfunction, evaluated as urea and creatinine levels, correlated with a reduced extent of tubular damage in $\mathrm{CCR} 1^{-1-}$ mice.

\section{Myeloid Cell Infiltration Is Dampened in $\mathrm{CCR}^{-/-}$Mouse Kidney}

Because leukocyte subpopulations, such as PMNs and monocytes, are implicated in the pathogenesis of HUS, immunostaining was performed to analyze early myeloid cell infiltration into the renal tissue. Immunofluorescence staining indicates more accumulation of interstitial $\mathrm{CD}_{11 \mathrm{~b}^{+}}$cells in renal tissue from control than from $\mathrm{CCR}^{-1-}$ mice 24 hours after Stx2 treatment (Figure 2, A and $B$ ). According to Ly6G staining, more PMNs were also observed in control compared with $\mathrm{CCR} 1^{-1-}$ mice (Figure 2, C and D). Before Stx2 injection, there were no differences in the number of these cells in both mouse strains (data not shown).

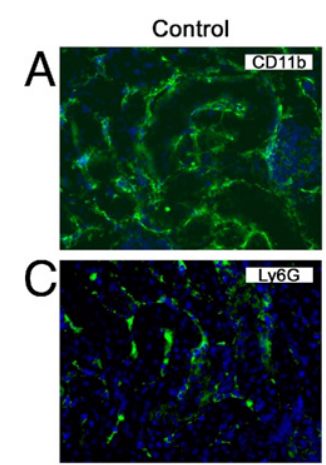

Control

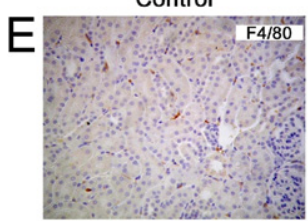

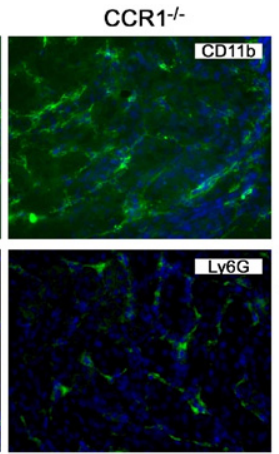

CCR1 $1-$

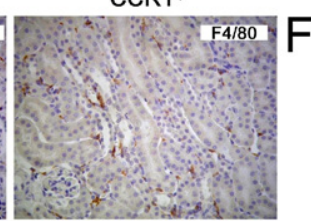

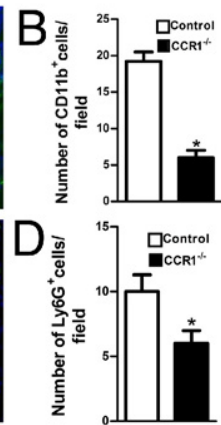

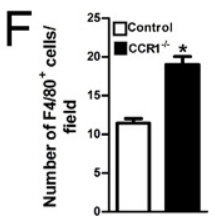

Figure 2. Leukocyte recruitment in kidney tissue. A: Representative microphotographs of CD11b immunofluorescent staining (green) of kidney cortex from control and CCR $1^{-/-}$mice 24 hours after Stx 2 intoxication. B: Quantification of the renal $\mathrm{CD}_{1} 1 \mathrm{~b}^{+}$myeloid cells $(n=5)$. C: Representative microphotographs of Ly6G immunofluorescent staining (green) of kidney cortex from control and CCR $1^{-/-}$mice 24 hours after Stx 2 intoxication. D: Quantification of the renal $\mathrm{Ly}_{6 \mathrm{G}}{ }^{+}$myeloid cells $(n=5)$. Nuclei were depicted using DAPI labeling (blue). Data represent the mean \pm SEM of absolute numbers quantified in three randomly selected fields. E: Representative microphotographs of F4/80 immunostaining to detect Mac/iDC 72 hours after Stx2 intoxication. F: Quantification of interstitial F4/ $80^{+}$cells in 20 cortical fields in control and CCR $1^{-/-}$mice 72 hours after Stx2 intoxication. Original magnification, $\times 200(\mathbf{E}$ and $\mathbf{F}) .{ }^{*} P<0.05$ versus control mice $(\mathbf{B}, \mathbf{D}$, and $\mathbf{F})$. 
A

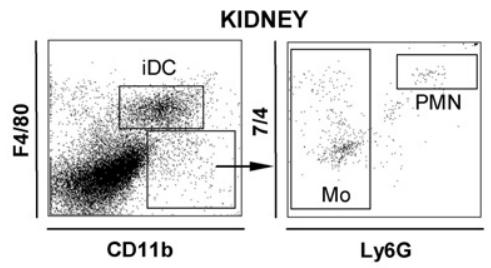

C

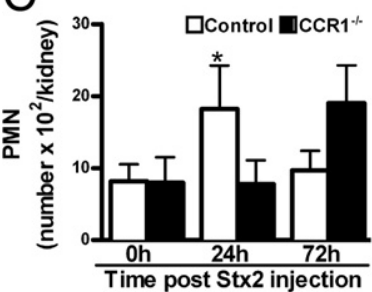

D
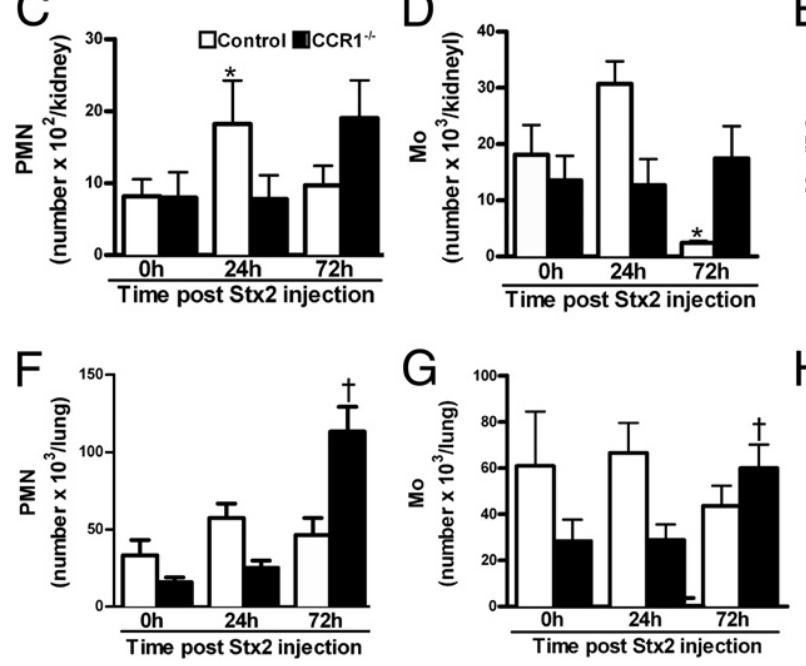

$\mathrm{E}$

B
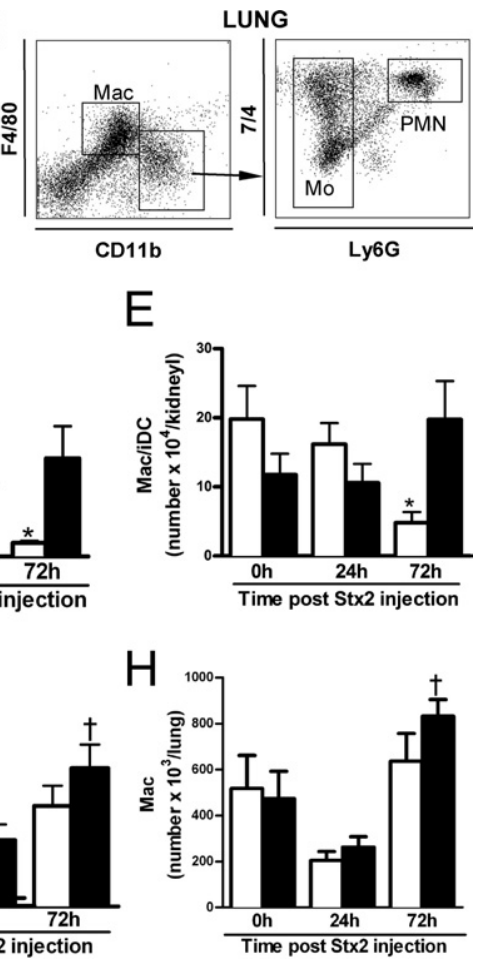

Figure 3. Leukocyte subsets in kidney and lung. CCR $1^{-/-}$and control mice were injected i.v. with Stx2. Kidneys and lungs were collected at different time points. A: Representative dot plot identifying PMNs $\left(\mathrm{CD} 11 \mathrm{~b}^{+}\right.$ $\mathrm{F} 4 / 80^{-} \mathrm{Ly}_{6 \mathrm{G}^{+}} 7 / 4^{+}$), monocytes (Mos; CD $11 b^{+} \mathrm{F} 4 / 80^{-} \mathrm{Ly}_{6 \mathrm{G}^{-}} 7 / 4^{+}$), and Macs/iDCs $\left(\mathrm{CD} 11 \mathrm{~b}^{+} \mathrm{F} 4 / 80^{+} \mathrm{CD} 11 \mathrm{c}^{+}\right)$in kidney. B: Representative dot plot identifying PMNs $\left(\right.$ CD $11 b^{+}$ F4/80- $\left.\mathrm{Ly}^{-} \mathrm{G}^{+} 7 / 4^{+}\right), \quad \mathrm{Mos} \quad\left(\mathrm{CD} 11 \mathrm{~b}^{+} \mathrm{F} 4 /\right.$ $\left.80^{-} \mathrm{Ly}_{6 \mathrm{G}}{ }^{-} 7 / 4^{+}\right)$, and $\mathrm{Macs}\left(\mathrm{F} 4 / 80^{+} \mathrm{CD} 11 \mathrm{~b}^{+}\right)$ in lung. Kidney cells were analyzed by flow cytometry, and the absolute number of PMNs (C), Mos (D), and Macs/iDCs (E) was calculated as detailed in Materials and Methods. Lung cells were analyzed by flow cytometry, and the absolute number of PMNs (F), Mos (G), and Macs (H) was similarly calculated. Data represent the mean \pm SEM of absolute numbers in each group $(n=10) .{ }^{*} P<0.05$ versus control before Stx2 intoxication (0 hours); ${ }^{\dagger} P<0.05$ versus CCR $1^{-/-}$before Stx 2 intoxication (0 hours)
To further analyze Mac populations, immunohistochemical (IHC) detection with anti-F4/80 antibody was performed before and at different times after Stx2 injection. Interestingly, fewer $\mathrm{F} 4 / 80^{+}$cells were observed in the renal interstitium of control mice compared with CCR $1^{-1-}$ mice at 72 hours after Stx2 injection (Figure 2, $E$ and $F$ ), whereas no differences were observed at earlier times (data not shown).

To confirm and quantify myeloid cell infiltration in kidney, the presence of PMNs, monocytes, and Macs/interstitial dendritic cells (Macs/iDCs) in this organ was analyzed by flow cytometry. PMNs were defined as cells expressing the myeloid marker CD11b and the specific antigens Ly6G and 7/4, whereas monocytes express CD11b and 7/4, but not Ly6G (Figure 3A). We identified Macs as cells expressing the conventional markers F4/80 and CD11b. However, because most of this cell population also expresses the common DC marker CD11c, we generically called this subset Mac/iDC, in agreement with previous reports. ${ }^{30} \mathrm{Stx} 2$ induced a transient increase of PMNs (Figure 3C) and monocytes (Figure 3D) in the kidney of control mice, peaking at 24 hours, followed by a decrease of these myeloid populations. Macs/iDCs only showed a significant decrease at 72 hours after Stx2 injection (Figure 3E). CCR1 $1^{-/-}$mice showed increased PMN and Mac/iDC populations in kidney at 72 hours, whereas monocytes were unchanged at all time points (Figure 3, C-E).

In parallel, the recruitment of myeloid cells in the lung, which is considered the major endothelial bed in which activated PMNs usually adhere, was studied. PMNs and monocytes from lung were identified following the same staining performed for kidney samples. CD11 $\mathrm{b}^{+}$and F4/ $80^{+}$cells from lung include mainly interstitial and alveolar
Macs, ${ }^{31}$ and were defined generically as Macs (Figure 3B). Control mice had no significant variations in the number of lung-associated leukocytes along the indicated experimental time, whereas $\mathrm{CCR} 1^{-1-}$ mice showed a significant increase of PMNs (Figure 3F), monocytes (Figure 3G), and Macs (Figure 3H) 72 hours after Stx2 injection.

\section{Myeloid Cell Populations Are Differently Altered in Blood and Bone Marrow from Control and CCR $1^{-/-}$Mice after Stx2 Injection}

To study whether myeloid cells, such as PMNs and monocytes, were differently mobilized in control and $\mathrm{CCR}^{-1-}$ mice, cells from peripheral blood and bone marrow were counted and analyzed by flow cytometry at different times after Stx2 injection. PMNs and monocytes were defined according to the CD11b, Ly6G, and $7 / 4$ expression in blood (Figure 4A) and bone marrow (Figure 4D), as previously described. Control mice showed an early and marked increase in peripheral PMNs (Figure 4B) and monocytes (Figure 4C), accompanied by a simultaneous reduction of both populations in bone marrow at 24 hours (Figure 4, E and F). After 72 hours, PMNs and monocytes were reduced in blood compared with initial values, and returned to baseline in bone marrow. By contrast, $\mathrm{CCR} 1^{-1-}$ mice only showed a significant, but delayed, increase of peripheral PMNs and a reduction of monocytes 72 hours after Stx2, compared with initial values (Figure 4, B and C). In parallel, there was an early reduction of both subpopulations in bone marrow that was finally restored to normal levels, as happened in control mice (Figure 4, E and F). These data indicate that 
A

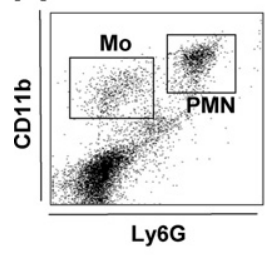

B

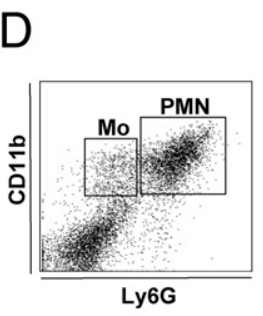

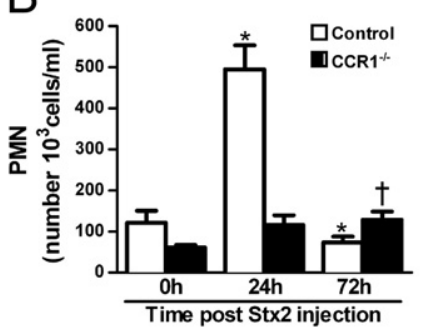

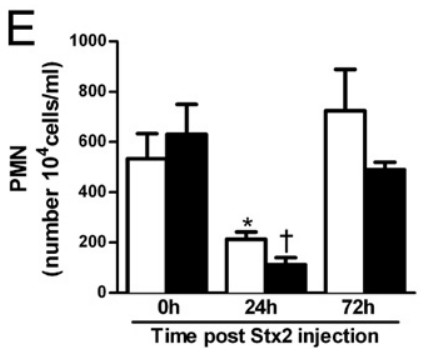

C

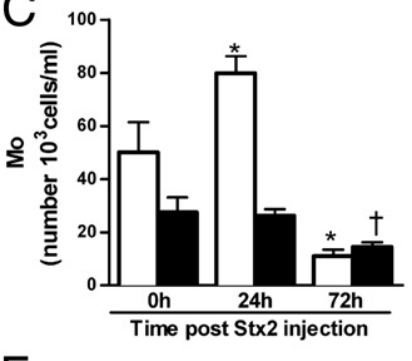

$\mathrm{F}$

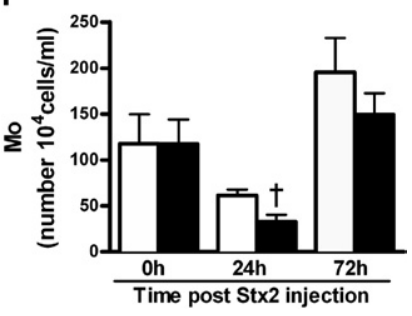

Figure 4. Leukocyte subsets in blood and bone marrow. Control and CCR $1^{-/-}$mice were injected i.v. with Stx2. Blood and bone marrow were collected before (0 hours) and at different times after Stx2 injection. Representative dot plots identifying PMNs $\left(\mathrm{CD} 11 \mathrm{~b}^{+} \mathrm{Ly}_{6 \mathrm{G}}{ }^{+}\right)$and monocytes (Mos; CD11b ${ }^{+} \mathrm{Ly}_{6 \mathrm{G}^{-}}$) in blood (A) and bone marrow (D). Cells were analyzed by flow cytometry, and absolute numbers of PMNs and Mos were calculated in blood (B and $\mathbf{C})$ and bone marrow (E and $\mathbf{F}$ ), as previously described in Materials and Methods. Data represent the mean \pm SEM of absolute numbers in each group $(n=10) .{ }^{*} P<0.05$ versus control before injection ( 0 hours); ${ }^{\dagger} P<0.05$ versus CCR $1^{-/-}$before injection ( 0 hours)
Stx2-triggered neutrophilia and monocytosis is dampened in CCR1-deficient mice.

\section{Inflammatory Cytokines Are Differently Expressed in Control and CCR1 ${ }^{-1-}$ Mice after Stx2 Injection}

To evaluate soluble parameters of inflammatory response, the level of cytokines, such as TNF- $\alpha$ and IL-6, was evaluated. For this purpose, both cytokines were tested in plasma from control and $\mathrm{CCR} 1^{-1-}$ mice at different points after Stx 2 injection. Plasmatic TNF- $\alpha$ (Figure 5A) and IL-6 (Figure 5B) levels increased rapidly at 2 and 24 hours, respectively, in control mice after Stx2 injection and returned to baseline thereafter. However, both cytokines were only increased at a later time point (72 hours) in $\mathrm{CCR} 1^{-1-}$ mice, suggesting that the inflammatory onset is delayed in $\mathrm{CCR} 1^{-1-}$ mice.

\section{Discussion}

The present work showed that the chemokine receptor CCR1 plays an important role during HUS evolution. Mice deficient in CCR1 had an increased survival rate after Stx2 injection compared with control mice. We also observed that $\mathrm{CCR} 1^{-1-}$ mice had an increased survival rate compared with $\mathrm{CCR} 5^{-1-}$ mice, suggesting that the absence of CCR5 may not be essential to the onset of HUS. Although both receptors share their main ligands (CCL3 and CCL5), the pattern of cellular expression is different. In particular, although CCR1 is expressed by monocytes, Macs, and PMNs, CCR5 expression is absent in PMNs. In addition, differential expression of CCR 1 and CCR5 has been reported in different subsets of monocytes, suggesting a sequential influx of monocytes/Macs with different functional capacities. ${ }^{32}$ For example, the blockade of CCR5 with soluble antagonists, such as Met-regulated on activation normal T-cell expressed and secreted, during experimental glomerulonephritis reduced $\mathrm{CCR}^{+}$
Macs into glomeruli. ${ }^{32}$ However, mice still develop severe histopathological lesions. These results suggest that $\mathrm{CCR}^{+}$Macs participate in the removal of apoptotic cells protecting tissues from the toxic content of dying cells. In addition, CCR5 mediates glomerular, but not interstitial, Mac recruitment in murine nephritis. ${ }^{32}$ Resistance in $\mathrm{CCR}^{-1-}$ mice to Stx2 intoxication was related to reduced renal damage, evaluated through plasmatic urea and creatinine levels, and kidney histological features. In a similar HUS murine model using a combination of Stx and lipopolysaccharide injection, renal expression of CCL3, CCL5, and CCL2 correlates with Mac infiltrate and blockade of these chemokines reduces such cell accu-
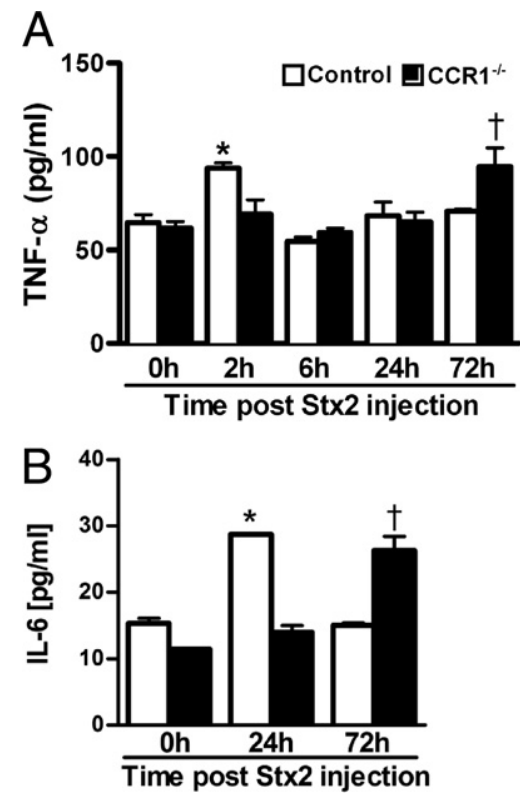

Figure 5. Cytokine expression in plasma from control and CCR $1^{-/-}$mice after Stx 2 injection. TNF- $\alpha(\mathbf{A})$ and IL-6 (B) were evaluated in plasma from control and CCR $1^{-1-}$ mice. Samples were obtained before and at indicated times after Stx2 injection. Data represent the mean \pm SEM of absolute numbers in each group $(n=10)$. ${ }^{*} P<0.001$ versus control before Stx injection ( 0 hours); ${ }^{\dagger} P<0.05$ versus $\mathrm{CCR} 1^{-/-}$before Stx injection ( 0 hours). 
mulation. ${ }^{23}$ Although the central pathological injury in children with HUS is at the glomerular level, Stx-treated mice show lesions in tubules, with little or no glomerular pathological features. ${ }^{33}$ Moreover, tubular lesions in mice given Stx2 predominantly affect renal cortical proximal tubules, with cortical distal tubules being relatively unaffected. The development of tubular injury can be explained by the localization of the Stx receptors, mainly on mouse renal tubules. In line with these reports, 72 hours after Stx2 treatment, we observed more severe tubular than glomerular lesions in both mouse strains. In many animal models of inflammatory kidney disease, such as unilateral ureteral obstruction ${ }^{34,35}$ and murine doxorubicin (Adriamycin) nephropathy, ${ }^{36}$ CCR1 blockade markedly reduces Mac and T-cell infiltrates, tubular injury, and interstitial fibrosis, but not glomerular pathological features. Likewise, we observed that CCR1 deficiency results in reduced renal leukocyte recruitment and reduced tubular damage but a similar level of glomerular congestion than control mice.

Previous studies have implicated CCR1 in the modulation of leukocyte trafficking and activation ${ }^{37}$ and in the balance of types 1 and 2 cytokines during infections. ${ }^{38,39}$ During HUS, a successful response to infection consists of a delicate balance between pro- and anti-inflammatory cytokines ${ }^{40,41}$ because an exacerbated inflammatory response mediated by leukocytes and cytokines/chemokines contributes to potentiate Stx-triggered endothelial damage..$^{9,10}$

Analysis of tissue-associated leukocytes demonstrated that Stx2 treatment induces an early trafficking of PMNs and monocytes to the kidney in control, but not in $\mathrm{CCR} 1^{-1-}$, mice. On the other hand, CCR $1^{-1-}$ mice had a delayed and slight increase of kidney leukocytes 72 hours after injection. Previous studies ${ }^{38}$ have shown that PMNs from $\mathrm{CCR}^{-1-}$ mice are nonresponsive to CCL3 and that CCR1 may be essential for influx of these cells to the injured tissues. Down-regulation of PMN influx to kidney may contribute to the protection against Stx2 toxicity in CCR $1^{-1-}$ mice. When monocytes and Macs/iDCs were analyzed, control mice showed a reduction in both cell subsets 72 hours after Stx 2 control mice. These reductions could be attributed to apoptosis of these cell subsets after activation, accompanying the beginning of the resolution of the inflammatory reaction. ${ }^{42,43}$ However, CCR $1^{-1-}$ mice showed a slight increase in the number of monocytes and Macs/iDCs. Further studies are needed to define the molecular mechanism leading to accumulation of these cell subsets in CCR $1^{-1-}$ mouse kidney. Whether this delayed infiltration is mediated by other chemokine axis and may favor fibrosis and repair remains to be elucidated. Renal iDCs may contribute to the recovery process by a dynamic phenotypic change from pro-inflammatory to anti-inflammatory. In this regard, during ischemia-/reperfusion-induced acute kidney injury, depletion of iDCs was associated with persistent renal damage, more apoptosis, inflammation, and impaired tubular proliferation. ${ }^{43}$ Considering this, we suggest that early increase of renal content of inflammatory cells may contribute to renal damage through induction of apoptosis and/or necrosis of renal cells and local inflammation.
Leukocyte activation and adherence to endothelium were simultaneously evaluated through lung content of the myeloid populations. PMNs, monocytes, and Macs were increased in lungs from CCR $1^{-1-}$ mice just at 72 hours after Stx2 injection, following the same kinetic pattern observed in the kidneys from these mice. On the other hand, control mice showed no significant alterations in the recruitment of cells into lung. These data suggest that Stx2 also induces activation of myeloid cells in CCR $1^{-1-}$ mice, demonstrated by cells with increased adhesive properties to lung vessels, which are known as the major marginal pool of PMNs. However, in the absence of CCR1 chemoattractant axis, marginated cells may not infiltrate tissue. Unfortunately, we could not distinguish marginated from infiltrated or transmigrated cells in lungs using flow cytometry to confirm this hypothesis. Likewise, in the ischemia-reperfusion kidney model of acute renal damage, there is an enhanced number of PMNs in the lung that are not infiltrating the tissue; for this reason, cells probably do not induce injury. ${ }^{30}$ Furthermore, lung Macs could be defined as interstitial Macs (F4/ $\left.80^{+} \mathrm{CD} 11 \mathrm{c}^{-}\right)$and alveolar Macs $\left(\mathrm{F} 4 / 80^{+} \mathrm{CD} 11 \mathrm{c}^{+}\right)$. These Mac populations show anti-inflammatory profiles by producing high levels of IL-10 or by interfering with lung DC function. ${ }^{31}$ These reports suggest that accumulation of Macs in lung, as we observed in $\mathrm{CCR} 1^{-1-}$ Stx2-treated mice, is not strictly related to a severe pulmonary disease.

Because there is considerable evidence that PMNs and monocytes play an active role in the pathogenesis of HUS, and both subpopulations express CCR1, they were analyzed in $\mathrm{CCR} 1^{-1-}$ and control mice after Stx2 injection. Although both strains showed mobilization of these cell subsets from bone marrow to periphery as a consequence of systemic Stx2 injection, the kinetics and intensity of such phenomenon were different. Interestingly, the severe and early neutrophilia observed in control mice was delayed and reduced in CCR $1^{-1-}$ mice. In addition, monocytes were only increased in control mice. These alterations were accompanied by the transitory depletion of PMNs and monocytes in the bone marrow. Although this process occurred in both mouse strains, CCR $1^{-1-}$ mice showed a more pronounced decrease and a slower recovery of normal cellularity compared with control mice. In this regard, it was previously demonstrated that Stx2-induced neutrophilia arose from different events, including acceleration in the release of bone marrow cells and increase in the proliferation of progenitor myeloid cells. ${ }^{44}$ CCL3, one of the main ligands for CCR1, has mediated proliferation of mature progenitor cells in bone marrow. ${ }^{38}$ Decreased numbers of progenitors of granulocytes and Macs have been observed in the spleen and blood of the CCR $1^{-1-}$ mice. ${ }^{38}$ All these events could be limiting the neutrophilia and monocytosis in $\mathrm{CCR} 1^{-1-}$ mice. We have previously reported that depletion of PMNs or Macs increases mouse survival to Stx2. ${ }^{9,10}$ We propose that a reduced neutrophilia and monocytosis at the beginning could be associated with a decrease in renal damage in deficient mice. Moreover, the inflammatory microenvironment inside the kidney induced an early and specific recruitment of myeloid cells to this organ 
solely in control mice. Cytokines, such as TNF- $\alpha$ and IL-6, which are usually up-regulated during a systemic inflammatory response and also in patients with HUS, ${ }^{45}$ were analyzed in plasma from Stx2-treated mice. In particular, TNF- $\alpha$, a critical cytokine involved in triggering the inflammation and in sensitizing endothelium to Stx action, is induced on Stx2 interaction with monocytes and renal epithelial cells. ${ }^{46,47}$ In agreement with this, we observed an early and transient increase of plasmatic TNF- $\alpha$ and IL-6 levels in control mice. However, the peak of both cytokines was delayed up to 72 hours in $\mathrm{CCR} 1^{-1-}$ mice. Therefore, results presented herein suggest that CCR 1 is necessary for cell recruitment and for amplification of local and systemic inflammatory response.

Previous reports in a murine model of sepsis have shown an altered cytokine/chemokine profile in CCR $1^{-/-}$ mice. Lower levels of CXCL2/Mac inflammatory protein-2 and $\mathrm{KC}$, both cytokines implicated in PMN recruitment, and also TNF- $\alpha$ were observed in $\mathrm{CCR} 1^{-I-}$ compared with control mice. ${ }^{39} \mathrm{An}$ interesting feature of our findings is that a dampened and delayed inflammatory response, evidenced through a delayed increase in circulating cytokines and mobilization of myeloid cells, may have a pronounced effect on the outcome of HUS. In this regard, previous reports ${ }^{9,10,48}$ have indicated that the simultaneous action of Stx and the inflammatory factors are essential and necessary to HUS development.

At present, apart from supportive therapy, there are no specific treatments for HUS. ${ }^{49}$ The knowledge about relevant components of host response involved in HUS pathogenesis could be useful for developing new therapeutic strategies for children who are infected with Stx-producing E. coli bacteria. Because most chemokine receptors bind multiple pro-inflammatory chemokines, therapeutic blockade of chemokine receptors, rather than individual chemokines, may be the preferred strategy to interfere with leukocyte recruitment to sites of tissue injury. Considering the results presented herein, we conclude that single blockade of CCR1 is important to the future design of alternative therapies to control kidney-specific infiltration of inflammatory cells involved in HUS.

\section{Acknowledgments}

We thank the Ministerio de Ciencia, Tecnologia e Innovacion Productiva, and Évaluation-Orientation de la Coopération Scientifique collaboration program; Romina Fraiman for collaborating in the edition of digital images; and Catherine Sofianides for language review of the manuscript.

\section{References}

1. Noris M, Remuzzi G: Hemolytic uremic syndrome. J Am Soc Nephrol 2005, 16:1035-1050

2. Tarr PI, Gordon CA, Chandler WL: Shiga-toxin-producing Escherichia coli and haemolytic uraemic syndrome. Lancet 2005, 365:1073-1086

3. Siegler R, Oakes R: Hemolytic uremic syndrome: pathogenesis, treatment, and outcome. Curr Opin Pediatr 2005, 17:200-204
4. Rivas M, Miliwebsky E, Chinen I, Deza N, Leotta GA: The epidemiology of hemolytic uremic syndrome in Argentina: diagnosis of the etiologic agent, reservoirs and routes of transmission [in Spanish] Medicina (B Aires) 2006, 66(Suppl 3):27-32

5. Mead PS, Griffin PM: Escherichia coli O157: H7. Lancet 1998, 352 1207-1212

6. Ruggenenti P, Noris M, Remuzzi G: Thrombotic microangiopathy, hemolytic uremic syndrome, and thrombotic thrombocytopenic purpura. Kidney Int 2001, 60:831-846

7. van Setten PA, van Hinsbergh VW, van der Velden TJ, van de Kar NC Vermeer M, Mahan JD, Assmann KJ, van den Heuvel LP, Monnens LA: Effects of TNF alpha on verocytotoxin cytotoxicity in purified human glomerular microvascular endothelial cells. Kidney Int 1997 51:1245-1256

8. van Setten PA, Monnens LA, Verstraten RG, van den Heuvel LP, van Hinsbergh VW: Effects of verocytotoxin-1 on nonadherent human monocytes: binding characteristics, protein synthesis, and induction of cytokine release. Blood 1996, 88:174-183

9. Fernandez GC, Lopez MF, Gomez SA, Ramos MV, Bentancor LV, Fernandez-Brando RJ, Landoni VI, Dran GI, Meiss R, Isturiz MA, Palermo MS: Relevance of neutrophils in the murine model of haemolytic uraemic syndrome: mechanisms involved in Shiga toxin type 2-induced neutrophilia. Clin Exp Immunol 2006, 146:76-84

10. Palermo MS, Alves Rosa MF, Van Rooijen N, Isturiz MA: Depletion of liver and splenic macrophages reduces the lethality of Shiga toxin-2 in a mouse model. Clin Exp Immunol 1999, 116:462-467

11. Fitzpatrick MM, Shah V, Trompeter RS, Dillon MJ, Barratt TM: Interleukin-8 and polymorphoneutrophil leucocyte activation in hemolytic uremic syndrome of childhood. Kidney Int 1992, 42:951-956

12. Forsyth KD, Simpson AC, Fitzpatrick MM, Barratt TM, Levinsky RJ: Neutrophil-mediated endothelial injury in haemolytic uraemic syndrome. Lancet 1989, 2:411-414

13. Inward CD, Howie AJ, Fitzpatrick MM, Rafaat F, Milford DV, Taylor CM; British Association for Paediatric Nephrology: Renal histopathology in fatal cases of diarrhoea-associated haemolytic uraemic syndrome. Pediatr Nephrol 1997, 11:556-559

14. van Setten PA, van Hinsbergh VW, van den Heuvel LP, Preyers F, Dijkman HB, Assmann KJ, van der Velden TJ, Monnens LA: Monocyte chemoattractant protein-1 and interleukin-8 levels in urine and serum of patents with hemolytic uremic syndrome. Pediatr Res 1998, 43: 759-767

15. Roche JK, Keepers TR, Gross LK, Seaner RM, Obrig TG: CXCL1/KC and CXCL2/MIP-2 are critical effectors and potential targets for therapy of Escherichia coli O157: H7-associated renal inflammation. Am J Pathol 2007, 170:526-537

16. Zoja C, Angioletti S, Donadelli R, Zanchi C, Tomasoni S, Binda E, Imberti B, te Loo M, Monnens L, Remuzzi G, Morigi M: Shiga toxin-2 triggers endothelial leukocyte adhesion and transmigration via NFkappaB dependent up-regulation of IL-8 and MCP-1. Kidney Int 2002 62:846-856

17. Ramos MV, Fernandez GC, Patey N, Schierloh P, Exeni R, Grimoldi I, Vallejo G, Elias-Costa C, Del Carmen Sasiain M, Trachtman H, Combadiere C, Proulx F, Palermo MS: Involvement of the fractalkine pathway in the pathogenesis of childhood hemolytic uremic syndrome. Blood 2007, 109:2438-2445

18. Zanchi C, Zoja C, Morigi M, Valsecchi F, Liu XY, Rottoli D, Locatelli M, Buelli S, Pezzotta A, Mapelli P, Geelen J, Remuzzi G, Hawiger J: Fractalkine and CX3CR1 mediate leukocyte capture by endothelium in response to Shiga toxin. J Immunol 2008, 181:1460-1469

19. Anders HJ, Ninichuk V, Schlondorff D: Progression of kidney disease: blocking leukocyte recruitment with chemokine receptor CCR1 antagonists. Kidney Int 2006, 69:29-32

20. Neote K, DiGregorio D, Mak JY, Horuk R, Schall TJ: Molecular cloning, functional expression, and signaling characteristics of a $\mathrm{C}-\mathrm{C}$ chemokine receptor. Cell 1993, 72:415-425

21. Gao JL, Murphy PM: Cloning and differential tissue-specific expression of three mouse beta chemokine receptor-like genes, including the gene for a functional macrophage inflammatory protein-1 alpha receptor. J Biol Chem 1995, 270:17494-17501

22. Gao JL, Sen Al, Kitaura M, Yoshie O, Rothenberg ME, Murphy PM, Luster AD: Identification of a mouse eosinophil receptor for the CC chemokine eotaxin. Biochem Biophys Res Commun 1996, 223:679684 
23. Keepers TR, Gross LK, Obrig TG: Monocyte chemoattractant protein 1, macrophage inflammatory protein 1 alpha, and RANTES recruit macrophages to the kidney in a mouse model of hemolytic-uremic syndrome. Infect Immun 2007, 75:1229-1236

24. Danforth JM, Strieter RM, Kunkel SL, Arenberg DA, VanOtteren GM, Standiford TJ: Macrophage inflammatory protein-1 alpha expression in vivo and in vitro: the role of lipoteichoic acid. Clin Immunol Immunopathol 1995, 74:77-83

25. Gao JL, Kuhns DB, Tiffany HL, McDermott D, Li X, Francke U, Murphy PM: Structure and functional expression of the human macrophage inflammatory protein 1 alpha/RANTES receptor. J Exp Med 1993, 177:1421-1427

26. Kasama T, Strieter RM, Standiford TJ, Burdick MD, Kunkel SL: Expression and regulation of human neutrophil-derived macrophage inflammatory protein 1 alpha. J Exp Med 1993, 178:63-72

27. Kuziel WA, Dawson TC, Quinones M, Garavito E, Chenaux G, Ahuja SS, Reddick RL, Maeda N: CCR5 deficiency is not protective in the early stages of atherogenesis in apoE knockout mice. Atherosclerosis 2003, 167:25-32

28. Capozzo AV, Pistone Creydt V, Dran G, Fernandez G, Gomez S, Bentancor LV, Rubel C, Ibarra C, Isturiz M, Palermo MS: Development of DNA vaccines against hemolytic-uremic syndrome in a murine model. Infect Immun 2003, 71:3971-3978

29. Karmali MA, Petric M, Lim C, Fleming PC, Arbus GS, Lior H: The association between idiopathic hemolytic uremic syndrome and infection by verotoxin-producing Escherichia coli. J Infect Dis 1985, 151:775-782

30. Awad AS, Rouse M, Huang L, Vergis AL, Reutershan J, Cathro HP, Linden J, Okusa MD: Compartmentalization of neutrophils in the kidney and lung following acute ischemic kidney injury. Kidney Int 2009, 75:689-698

31. Bedoret D, Wallemacq H, Marichal T, Desmet C, Quesada Calvo F, Henry E, Closset R, Dewals B, Thielen C, Gustin P, de Leval L, Van Rooijen N, Le Moine A, Vanderplasschen A, Cataldo D, Drion PV Moser M, Lekeux P, Bureau F: Lung interstitial macrophages alter dendritic cell functions to prevent airway allergy in mice. J Clin Invest 2009, 119:3723-3738

32. Anders HJ, Frink M, Linde $Y$, Banas B, Wornle M, Cohen CD, Vielhauer V, Nelson PJ, Grone HJ, Schlondorff D: CC chemokine ligand 5/RANTES chemokine antagonists aggravate glomerulonephritis despite reduction of glomerular leukocyte infiltration. J Immunol 2003, 170:5658-5666

33. Paixao-Cavalcante D, Botto M, Cook HT, Pickering MC: Shiga toxin-2 results in renal tubular injury but not thrombotic microangiopathy in heterozygous factor $\mathrm{H}$-deficient mice. Clin Exp Immunol 2009, 155: 339-347

34. Anders HJ, Vielhauer V, Frink M, Linde Y, Cohen CD, Blattner SM, Kretzler M, Strutz F, Mack M, Grone HJ, Onuffer J, Horuk R, Nelson PJ, Schlondorff D: A chemokine receptor CCR-1 antagonist reduces renal fibrosis after unilateral ureter ligation. J Clin Invest 2002, 109: 251-259

35. Eis V, Luckow B, Vielhauer V, Siveke JT, Linde Y, Segerer S, Perez De Lema G, Cohen CD, Kretzler M, Mack M, Horuk R, Murphy PM, Gao JL, Hudkins KL, Alpers CE, Grone HJ, Schlondorff D, Anders HJ: Chemokine receptor CCR1 but not CCR5 mediates leukocyte recruitment and subsequent renal fibrosis after unilateral ureteral obstruction. J Am Soc Nephrol 2004, 15:337-347
36. Anders HJ, Belemezova E, Eis V, Segerer S, Vielhauer V, Perez de Lema G, Kretzler M, Cohen CD, Frink M, Horuk R, Hudkins KL, Alpers CE, Mampaso F, Schlondorff D: Late onset of treatment with a chemokine receptor CCR1 antagonist prevents progression of lupus nephritis in MRL-Fas(Ipr) mice. J Am Soc Nephrol 2004, 15:1504-1513

37. Shang X, Qiu B, Frait KA, Hu JS, Sonstein J, Curtis JL, Lu B, Gerard C, Chensue SW: Chemokine receptor 1 knockout abrogates natural killer cell recruitment and impairs type-1 cytokines in lymphoid tissue during pulmonary granuloma formation. Am J Pathol 2000, 157:20552063

38. Gao JL, Wynn TA, Chang Y, Lee EJ, Broxmeyer HE, Cooper S, Tiffany $\mathrm{HL}$, Westphal H, Kwon-Chung J, Murphy PM: Impaired host defense, hematopoiesis, granulomatous inflammation and type 1-type 2 cytokine balance in mice lacking CC chemokine receptor 1. J Exp Med 1997, 185:1959-1968

39. Ness TL, Carpenter KJ, Ewing JL, Gerard CJ, Hogaboam CM, Kunkel SL: CCR1 and CC chemokine ligand 5 interactions exacerbate innate immune responses during sepsis. J Immunol 2004, 173:6938-6948

40. Inward CD, Varagunam M, Adu D, Milford DV, Taylor CM: Cytokines in haemolytic uraemic syndrome associated with verocytotoxin-producing Escherichia coli infection. Arch Dis Child 1997, 77:145-147

41. Murata A, Shimazu T, Yamamoto T, Taenaka N, Nagayama K, Honda T, Sugimoto H, Monden M, Matsuura N, Okada S: Profiles of circulating inflammatory- and anti-inflammatory cytokines in patients with hemolytic uremic syndrome due to $\mathrm{E}$. coli $\mathrm{O} 157$ infection. Cytokine 1998, 10:544-548

42. Ferenbach D, Kluth DC, Hughes J: Inflammatory cells in renal injury and repair. Semin Nephrol 2007, 27:250-259

43. Kim MG, Boo CS, Ko YS, Lee HY, Cho WY, Kim HK, Jo SK: Depletion of kidney $\mathrm{CD}_{11 \mathrm{C}^{+}} \mathrm{F} 4 / 80^{+}$cells impairs the recovery process in ischaemia/reperfusion-induced acute kidney injury. Nephrol Dial Transplant 2010, 25:2908-2921

44. Fernandez GC, Rubel C, Dran G, Gomez S, Isturiz MA, Palermo MS: Shiga toxin-2 induces neutrophilia and neutrophil activation in a murine model of hemolytic uremic syndrome. Clin Immunol 2000, 95: 227-234

45. Karpman D, Andreasson A, Thysell H, Kaplan BS, Svanborg C: Cytokines in childhood hemolytic uremic syndrome and thrombotic thrombocytopenic purpura. Pediatr Nephrol 1995, 9:694-699

46. Hughes AK, Stricklett PK, Kohan DE: Shiga toxin-1 regulation of cytokine production by human glomerular epithelial cells. Nephron 2001, 88:14-23

47. Foster GH, Armstrong CS, Sakiri R, Tesh VL: Shiga toxin-induced tumor necrosis factor alpha expression: requirement for toxin enzymatic activity and monocyte protein kinase $\mathrm{C}$ and protein tyrosine kinases. Infect Immun 2000, 68:5183-5189

48. Palermo M, Alves-Rosa F, Rubel C, Fernandez GC, FernandezAlonso G, Alberto F, Rivas M, Isturiz M: Pretreatment of mice with lipopolysaccharide (LPS) or IL-1beta exerts dose-dependent opposite effects on Shiga toxin-2 lethality. Clin Exp Immunol 2000, 119: $77-83$

49. Michael M, Elliott EJ, Craig JC, Ridley G, Hodson EM: Interventions for hemolytic uremic syndrome and thrombotic thrombocytopenic purpura: a systematic review of randomized controlled trials. Am J Kidney Dis 2009, 53:259-272 